\title{
Теория и экономика медиа как актуальные направления медиаисследований
}

\author{
Елена Вартанова
}

Созданная на факультете журналистики МГУ имени М.В. Ломоносова 15 лет назад кафедра теории и экономики средств массовой информации с первых дней существования активно включилась в научную работу факультета, сделав акцент на междисциплирных исследованиях. Изучая структурную, экономическую и управленческую трансформацию медиасистемы России, становление нового сегмента отечественной экономики - медиаиндустрии, исследования опирались на традиции анализа моделей медиа в различных общественных и политических системах, заложенные кафедрой истории зарубежной журналистики и литературы в 1970-1990 гг. По мере расширения тематики научной работы, охватывавшей изучение медиаиндустрии, экономики и менеджмента СМИ, встала задача разработки теоретических оснований отечественной теории медиа.

Исследования, проведенные в течение последних лет, концентрировались на изучении особенностей постсоветской трансформации отечественной медиаиндустрии (Иваницкий, 2010), на сравнительном анализе национальных индустрий СМИ ведущих экономик мира, стран БРИКС (Энциклопедия мировой индустрии СМИ, 2019, Медиасистемы стран БРИКС, 2018), на становлении экономической модели отечественных СМИ после социалистической революции, особенно в период НЭП (Бабюк, 2019), на формировании современных принципов управления редакцией (Вырковский, 2016), на анализе отдельных аспектов деятельности отечественного медиарынка - становлении актуальных форм собственности (Смирнов, 2014), развитии отдельных сегментов медиаиндустрии (Вырковский, Макеенко, 2014), прогнозе динамики медиабизнеса в условиях цифровизации (Индустрия российских медиа, 2017) и др. На основании проводившихся исследований были созданы учебники и учебные пособия, которые широко используются в журналистском образовании.

\section{Развитие теоретических подходов: промежуточные итоги}

Сегодня представители школы медиаисследований факультета журналистики МГУ все чаще склоняются к выделению в качестве основы объектного поля трех основных парадигм - эмпирико-функционализма, политэкономии СМИ и культурологии СМИ (или медиаантропологии) (Дунас, 2011 ; 2017). Конечно, это несколько схематичный подход, к тому же он разделяется не всеми, ряд других исследователей предлагает свою клас- 
сификацию теорий (Кирия, Новикова, 2017; Корконосенко, 2010), однако научная школа теории СМИ нашего факультета следует традиции, проявившейся во второй половине XX в., - выделять в качестве ключевых парадигм эмпирико-функционализм и политэкономию, что было предложено Д. МакКуэйлом 13). По мнению этого выдающегося теоретика массовой коммуникации, одна из доминирующих в XX в. теоретических парадигм политэкономическая. И именно она, как считают основоположники медиаэкономики, дала толчок изучению экономических особенностей медиа как индустрии, сегмента экономики, как системы предприятий, действующих на сдвоенном рынке товаров и услуг (Smythe, 1977; Picard, 1989).

Показательно, что выявление не только функционально-нормативных (традиция эмпирико-функционализма), но и организационно-экономических, властно-ресурсных (традиция политэкономии) особенностей СМИ приводит к необходимости более целостного исследования медиа. Одна из важных академических задач сегодня - институционализация медиаисследований в перечнях научных специальностей, формирование объектно-предметного поля этой области, создание и согласование актуального понятийного и концептуального аппарата (От теории журналистики к теории медиа, 2019; Вартанова, 2019).

В научных дискуссиях факультета журналистики МГУ уже почти десять лет назад была инициирована дискуссия о разведении и современном концептуальном наполнении понятий «журналистика», «средства массовой информации» («СМИ»), «медиа» (Лазутина, 2012; Отечественная теория медиа: основные понятия, 2019). И если в научных подходах в отношении к первым двум уже сложилось определенное академическое согласие (Землянова, 2004; Лазутина, 2010), то в трактовке понятия «медиа», которые часто рассматриваются как цифровые, как социальные медиа, еще много неясностей и различных интерпретаций (Макеенко, 2018). Именно в этом направлении развивались последние исследования кафедры теории и экономики средств массовой информации, изложенные в недавно вышедших в свет коллективных научных изданиях (От теории журналистики к теории медиа, 2019; Отечественная теория медиа: основные понятия, 2019).

Представляется, что теория медиа должна также анализировать и актуальные процессы, которые происходят сегодня в национальных и глобальной медиасистемах, на разных уровнях медиапространства. Поэтому важно выделить четыре процесса, которые становятся ключевыми в процессе построения теории современных медиа.

Во-первых, это масштабный процесс цифровизации всех сторон общественной жизни. Хотя цифровизация часто рассматривается в историческом контексте динамики прорывных технологий, преображающих экономические и общественные пространства, ее активное влияние на современное состояние бизнес-среды медиаиндустрии трудно переоценить. Сегодня фиксируются не только количественные изменения медиабизнеса (Вартанов, 2015), но и их переход в качественные трансформации, характеризующиеся появлением новых типов предприятий в медиа- 
индустрии, формированием новых стратегий развития медиабизнеса в условиях «цифры», выходом новых игроков на рынок, реструктуризацией редакционных бизнес-процессов (Вырковский, 2016; Индустрия российских медиа, 2017).

Во-вторых, это часто анализируемый сейчас процесс «медиатизации», который с недавних пор определяется как «глубокая медиатизация» и рассматривается как социальный метапроцесс, оказывающий разносторонние воздействия на функционирование общественных систем (Гуреева, 2017 ; 2018). Медиаиндустрия под влиянием этого процесса расширяется, аудиторные и социальные эффекты меняются, в результате медиатизация приобретает большие масштабы. Таким образом, ее осмысление как одного из самых актуальных процессов становится важной задачей построения теории медиа.

В-третьих, все чаще обсуждается современный этап процесса «медиасоциализации», обозначающего одну из форм социализации и уже давно присутствующего в качестве объекта анализа междисциплинарных гуманитарных исследований. В последнее время в связи с поколенческими изменениями в медиакультуре аудитории, с растущим запросом молодых поколений на социальные медиа, с цифровизацией повседневных медиапрактик аудитории, медиасоциализация превращается в один из ключевых процессов медиасреды (Дунас, Вартанов, Кульчицкая, Салихова и др., 2020; Dunas, Vartanov, 2020). Исследования показывают, что у современной молодежи наибольшим авторитетом пользуются уже не такие традиционные институты общества, как семья и школа, а социальные медиа - создаваемые ими новые круги и сообщества коммуникации и социального взаимодействия, опосредованные и медиатизированные (Вьюгина, 2017, Дунас, Вартанов, Кульчицкая, Салихова и др., 2019).

В-четвертых, все актуальнее становится осмысление природы «цифрового неравенства», и, соответственно, процесса его преодоления на разных уровнях и в разных национальных контекстах. Именно проблема «цифрового раскола», «цифрового разрыва» (digital divide) вытекала из представлений об «информационном богатстве» и «информационной бедности», которые рассматривались классической политэкономией медиа как последствия информационной революции в условиях сохраняющегося неравенства в обществе. Цифровое неравенство стало одним из центральных последствий взрывного развития ИКТ в 1980-1990 гг., и на протяжении десятилетий оно оставалось объектом внимания не только ученых, но и политиков и законодателей на национальном и глобальном уровне. Сегодня исследователи подошли к более комплексному пониманию этого явления, анализируя его на трех уровнях - уровне доступа к технологиям, уровне цифровой грамотности пользователей и уровне их умений получать пользу от использования цифровых медиатехнологий в своей профессиональной и частной жизни (Vartanova, Gladkova, 2019).

Становится очевидным, что медиа, занимая значительное место в жизни людей, с одной стороны, должны быть доступны всем, чтобы предотвратить социальное расслоение, основанное на неравном доступе к ин- 
формационно-коммуникационным ресурсам. С другой - использование медиа требует новых компетенций от аудитории, предоставляя ей при этом и новые возможности, которые трансформируются в новые виды социального капитала, все чаще определяемого как цифровой капитал (Вартанова, Гладкова, 2020). В этой связи важным с точки зрения теоретических подходов к медиа является проблема цифровой медиаграмотности, то есть нового аспекта грамотности современного человека, которая должна одновременно быть и инструментом развития, и инструментом безопасности в цифровой медиасреде.

Наряду с формированием и теоретизацией актуальных понятий и концептуальных подходов к медиа как значительному явлению современной жизни, важнейшей задачей кафедры в рамках теории медиа становится осмысление природы и динамики медиаиндустрии, трансформации индустриального комплекса под воздействием цифровизации.

\section{Изучение медиаиндустрии: дальнейшие векторы}

Теоретическое осмысление медиаэкономики предполагает, как отмечалось выше, академическое изучение СМИ как отдельной отрасли экономики, прежде всего рыночной (Picard, 1989; Albarran, 2010; Doyle, 2013). Это хоть и молодое, но весьма влиятельное и четко сфокусированное направление в медиаисследованиях. Над ним работают исследователи, представляющие ряд американских, немецких, французских, испанских, бразильских университетов, объединенных в международные ассоциации - International Media Management Academic Association (IMMAA), European Media Management Accosiation (EMMA). Давние партнеры факультета журналистики МГУ, они неоднократно проводили в Московском университете свои ежегодные конференции. A World Media Economics Conference (WMEC) - фактически уже не организация, а регулярно организуемый международный конгресс - приобрела авторитет исследовательского сообщества, определяющего для глобальной академической среды тематику и направления исследований.

Анализу медиаэкономики посвящены несколько авторитетных журналов, которые формируют академическую повестку данной научной области: Journal of Media Economics, Journal of Media Business Studies, International Journal of Media Management. В отличие от многих академических журналов, имеющих широкую теоретическую тематику, эти издания четко сфокусированы на медиаэкономике как объектно-предметном поле, что позволяет быстро и точно отслеживать меняющиеся направления исследований.

Используя опыт глобального академического сообщества исследователей данной области и учитывая потребности отечественной медиаиндустрии, рынка труда и профессий, следует выделить следующие перспективные направления исследований, которые обладают особой актуальностью. Среди них:

- Изучение меняющейся структуры отрасли: в новых условиях цифровизации требуется переосмысление классического положения Д. Смайта (1977) и Р. Пикара (1989) о СМИ как сдвоенном рынке товаров 
и услуг. С одной стороны, рынок развивается под воздействием цифровизации и технологических платформ (Facebook, YouTube), которые превращаются в новый тип предприятий медиаиндустрии и в новых влиятельных игроков, создающих своего рода надстройку, или, точнее, оболочку, над старыми игроками - традиционными медиакомпаниями. Причем платформы все больше забирают рекламные потоки, не производя контента, а просто создавая вокруг чужого контента свою технологическую оболочку; в этих условиях и сама медиаиндустрия должна рассматриваться в актуальной динамике складывания новой технологически детерминированной «экосистемы»;

- Эмпирическое изучение бизнес-моделей, направленное на построение новых теоретических моделей, с учетом идущей гибридизации, которая складывается из объединения традиционных и новых инструментов монетизации (здесь важно понимать особенности национальных и глобального медиарынков);

- Изучение структур собственности в медиабизнесе - это традиционная, но всегда актуальная тема, выросшая на основе политэкономического анализа. В медиаэкономике сейчас важны вопросы оптимальной структуры компании, оптимизации бизнес-процессов в рамках одного предприятия, выявления ядра деятельности в области традиционного медиабизнеса или в смежных медийных, а также немедийных производств;

- Исследование развития больших данных и искусственного интеллекта, их влияния на процессы в медиабизнесе; очевидно, что big data может изменить не только тематику медиаисследований, но и методологические подходы к ним;

- Анализ регулирования медиа, прежде всего в технологических и экономических аспектах функционирования медиаиндустрии и отдельных предприятий с учетом конвергенции разных отраслей.

\section{Смежные перспективные направления}

Наряду с развитием традиционной тематики изучения медиаиндустрий следует обратить внимание и на некоторые смежные проблемы, которые не могут рассматриваться вне изучения экономики и менеджмента СМИ.

Анализ медиасистем. Для понимания экономики медиа очень важна дискуссия о концепции медиасистемы, которая активно разворачивается в последнее время как в России, так и за рубежом. Концепция медиасистемы многими зарубежными коллегами воспринимается как устаревшая, при изучении медиа они призывают уходить от рамок национального государства и анализировать глобальные тренды и общие для всех стран мегапроцессы медиапространства, обращая внимание лишь на нюансы национальных контекстов, в которых медиа проявляют себя.

Однако во многих случаях это не вполне корректно. Так, российская медиасистема находится на ином этапе экономического развития, чем медиасистемы стран Западной Европы и США: регулирование у нас еще не устоялось, медиакапитал не сформировался, бизнес-модели не сложились. В отечественной медиасистеме особое место занимает государ- 
ственная собственность на СМИ - своего рода «третья модель» собственности наряду с частной и общественной, что практически не встречается в развитых медиаиндустриях Западной Европы и Северной Америки, но присутствует в странах Азии.

Исходя из большей детерминированности российской медиасистемы национальными факторами мы должны уделять значительное внимание мониторингу ее деятельности, регулированию, эконометрическому анализу, должны думать о прогнозе и предложениях по формированию стратегических направлений развития отрасли, изучать воздействие комплекса и отдельных факторов национальной специфики - таких как геополитические, географические, демографические, экономические, политические, регуляторные, технологические, культурные, этнические. В нашем понимании медиаиндустрия и медиасистема остаются очень близкими понятиями, изучать которые по отдельности невозможно.

Исследование аудитории. Изучение аудитории как экономической категории - это крайне актуальное сейчас направление. Спрос потребителя в его взаимодействии с предложением медиаконтента на медиарынке оказывает все большее влияние на отечественную медиаиндустрию. Если лет пятьдесят назад было очень легко формировать повестку СМИ и предлагать медиаконтент «сверху вниз», от медиакомпаний аудитории, то сегодня, особенно в условиях технологической революции и усиливающейся интерактивности, именно аудитория “снизу» формирует запрос.

Новая мотивация, изменение поколенческих ценностей и культуры медиапотребления, появление поколений «Зет» и «Альфа» - эти дискуссион ные вопросы заставляют обращать внимание на трансформацию запросов по медиаконтенту. Становится важным понять, можно ли применять в условиях цифровой среды классическую концепцию использования и удовлетворения (uses and gratifications) для того или иного поколения или она сохраняет универсальное значение для всей аудитории. Такая важная характеристика, как вовлеченность аудитории, становится особым индикатором поведения и взаимодействия аудитории с медиа. Она ярко проявляется в условиях фрагментации аудитории, персонализации медиа, именно она стала важнейшим KPI - ключевым экономическим индикатором современного медиабизнеса.

Управление редакцией. Сегодня формы трудовых отношений журналистов с редакцией, особенно в крупных городах, радикально изменились, причем нетрадиционные формы - частичная занятость, удаленная/дистанционная работа, отсутствие необходимости присутствовать в редакции, меняют взаимодействие медиакомпании, менеджеров, журналистов и аудитории. Несмотря на то, что исследование медиаменеджмента у нас активно развивается, изучение изменений структуры и организации работы редакций различных СМИ в условиях цифровой среды необходима постоянно. Актуален и вопрос осмысления инноваций в управлении редакционными процессами, роль искусственного интеллекта в современном производстве и распространении медиаконтента. Очевидно, речь 
идет о междисциплинарном поле, но экономический компонент на нем отнюдь не последний.

Экономика журналистики. Журналистика как одно из ключевых явлений медийного поля переживает сегодня радикальный экономический слом. Многие зарубежные исследователи говорят о том, что традиционная бизнес-модель журналистики, основанная на рекламе, умирает, о том, что аналитическая или расследовательская журналистика, которые «стоят» дорого, уже не могут зарабатывать в условиях рынка, когда реклама уходит в неинституционализированые социальные медиа.

Кризис традиционной журналистики все чаще заставляет размышлять о важности клиентской и дотационной моделей, о тех условиях, при которых журналист должен думать не о привлечении рекламы путем создания большой аудитории любыми способами, а о цели своей деятельности качестве материалов и социальной профессиональной ответственности. В последние годы важна исследовательская работа не просто по изучению моделей монетизации журналистского контента, но и по формулированию основ экономической модели журналистики. Возможно, через несколько лет это будет совершенно иная экономическая модель, базирующаяся на дотациях, налогах, общественной поддержке, поскольку сейчас журналистику все чаще относят к общественным благам, которые должны финансироваться обществом. И ключевой характеристикой такой модели станет гибридность, вероятно, и межпрофессиональная. Так, сейчас уже вполне допустима - и этически, и экономически - нативная реклама, которая по сути есть форма гибридизации контента и бизнес-модели.

Методологические вызовы. Следует остановиться и на методологических вызовах, с которыми сталкиваются исследователи. Вызовы определяются тем, что для разработки экономических и теоретических направлений нам необходимо использовать междисциплинарные подходы. Современным ученым необходим разнообразный инструментарий, применяемый в различных научных областях. Например, классические методы филологических исследований, которые традиционно использовались при изучении журналистики, должны взаимодействовать с методами экономического анализа, общей теорией менеджмента, с социологией, историей, психологией, теорией информации. Конечно, под каждое исследование и под каждую тему необходимо настраивать исследовательский инструментарий, но при этом он должен быть междисциплинарным.

Нужно привлекать математические методы, поскольку медиаиндустрия стала пространством big data и ее нужно анализировать соответствующими методами. Анализируя большие данные медиаиндустрии, можно увидеть много актуальных трендов, еще не выявленных аналитиками. Сочетание количественных и качественных методов это, конечно, доминанта медиаисследований, но какие и как, должны определять сами исследователи, и поэтому наши дальнейшие проекты будут в значительной степени зависеть от нашей методологической подготовки.

Исторический генезис, анализ современного состояния, прогноз на будущее - таков хронологический подход к изучению любого социального 
явления. В случае с анализом медиаиндустрии он оказывается важен не только с теоретической точки зрения. Проводимый в современном университете, он способствует подготовке будущих кадров для рынка труда, а также помогает отрасли увидеть закономерности и получить прогноз развития. В этом видит свою задачу и московская школа изучения теории, экономики и менеджмента СМИ, которую представляет факультет журналистики МГУ имени М.В. Ломоносова.

\section{Библиография}

Бабюк М.И. К вопросу о формах собственности на периодическую печать в СССР в условиях 1920-х гг. // Вестн. Моск. ун-та. Сер. 10: Журналистика. 2019. № 6. C. 25-51. DOI: 10.30547/vestnik.journ.6.2019.2551

Вартанов С.А. Динамика развития медиаиндустрии России в 2000-2014 гг.: общие тренды и взаимосвязь с макроэкономическими показателями // Медиаскоп. 2015. Вып. 3. Режим доступа: http://www.mediascope.ru/1831

Вартанова Е.Л. Теория медиа: отечественный дискурс. М.: Фак. журн. Мгу; Издво Моск. ун-та, 2019.

Вартанова Е.Л., Гладкова А.А. Цифровой капитал в контексте концепции нематериальных капиталов // Медиаскоп. 2020. Вып. 1. Режим доступа: http://www. mediascope.ru/2614 DOI: 10.30547/mediascope.1.2020.8

Вырковский А.В. Редакционный менеджмент в печатных и онлайновых массмедиа: процессный подход. М.: МедиаМир, 2016.

Вырковский А.В., Макеенко М.И. Региональное телевидение России на пороге цифровой эпохи. М.: МедиаМир, 2014.

Вьюгина Д.М. Особенности медиапотребления цифрового поколения России // Медиаскоп. 2017. Вып. 4. Режим доступа: http://www.mediascope.ru/2386

Гуреева А.Н. Концептуализация процесса медиатизации в России и за рубежом // МедиаАльманах. 2018. № 5. С. 24-31.

Гуреева А.Н. Медиатизация научно-образовательной деятельности в Интернете: сайт российского вуза // Вестн. Моск. ун-та. Сер. 10: Журналистика. 2017. № 3. C. 58-88.

Дунас Д.В. К вопросу о классификации теорий СМИ // Вестн. Моск. ун-та. Сер. 10: Журналистика. 2011. № 4. С. 27-41.

Дунас Д.В. Парадигмальный подход к изучению СМИ: опыт зарубежных исследователей // Вестн. Моск. ун-та. Сер. 10: Журналистика. 2017. № 3. С. 3-16.

Дунас Д.В., Вартанов С.А., Кульчицкая Д.Ю., Салихова Е.А. и др. Мотивационные факторы медиапотребления российской цифровой молодежи: результаты пилотного исследования // Вестн. Моск. ун-та. Сер. 10: Журналистика. 2020. № 2. C. 3-27.

Дунас Д.В., Вартанов С.А., Кульчицкая Д.Ю., Салихова Е.А. и др. Теоретические аспекты изучения медиапотребления российской молодежи: к пересмотру теории использования и удовлетворения // Вестн. Моск. ун-та. Сер. 10: Журналистика. 2019. № 2. С. 3-28. 
Землянова Л.М. Коммуникативистика и средства информации: Англо-русский толковый словарь концепций и терминов: М.: Изд-во Моск. ун-та, 2004.

Иваницкий В.Л. Модернизация журналистики: методологический этюд. М.: Издво Моск. ун-та. 2010.

Индустрия российских медиа: цифровое будущее / под ред. Е.Л. Вартановой. М.: МедиаМир, 2017.

Кирия И.В., Новикова А.А. История и теория медиа. М.: ИД Высш. шк. экон., 2017.

Корконосенко С. Г. Теория журналистики: моделирование и применение. М.: Логос, 2010.

Лазутина Г.В. Основы творческой деятельности журналиста. М.: Аспект Пресс, 2010.

Лазутина Г.В. Термины - хранилище концепции // Вестн. Моск. ун-та. Сер. 10: Журналистика. 2012. № 1. С. 41-59.

Макеенко М.И. Направления трансформации теоретических подходов в российских исследованиях влияния цифровизации на медиа // Медиаскоп. 2018. Вып. 3. Режим доступа: http://www.mediascope.ru/2463 DOI: 10.30547/ mediascope.3.2018.1

МакКуэйл Д. Журналистика и общество. М.: МедиаМир; Фак. журн. МГУ, 2013.

Медиасистемы стран БРИКС: исторический генезис, особенности функционирования / под ред. Е.Л. Вартановой. М.: Аспект Пресс, 2018.

От теории журналистики к теории медиа. Динамика медиаисследований в современной России / под ред. Е.Л. Вартановой. М.: Изд-во Моск. ун-та, 2019.

Отечественная теория медиа: основные понятия. Словарь / под ред. Е.Л. Вартановой. М.: Фак. журн. МГУ; Изд-во Моск. ун-та, 2019.

Смирнов С.С. Медиахолдинги России: национальный опыт концентрации СМИ. М.: МедиаМир, 2014.

Энциклопедия мировой индустрии СМИ / под ред. Е.Л. Вартановой. М.: Аспект Пресс. 2019.

Albarran A.B. (2010) The Media Economy. New York: Routledge,

Doyle G. (2013) Understanding Media Economics. London: Sage.

Dunas D., Vartanov S. (2020) Emerging Digital Media Culture in Russia: Modelling the Media Consumption of Generation Z. Journal of Multicultural Discourses. DOI: 10.1080/17447143.2020.1751648

Picard R.G. (1989) Media Economics: Concepts and Issues. Newbury Park, Calif.: Sage Publ. Smythe D.W. (1977) Communications: Blindespot of Western Marxism. Canadian Journal of Political and Society Theory 1(3): 1-28.

Vartanova E., Gladkova A. (2019) New Forms of the Digital Divide. In: J. Trappel (ed.) Digital Media Inequalities: Policies against Divides, Distrust and Discrimination. Goteborg: Nordicom, pp. 191-211. 